University of Nebraska - Lincoln

DigitalCommons@University of Nebraska - Lincoln

Biochemistry -- Faculty Publications

Biochemistry, Department of

8-1-2007

\title{
A systematic approach to the development of fluorescent contrast agents for optical imaging of mouse cancer models
}

Joy L. Kovar

LI-COR Biosciences, joy.kovar@licor.com

Melanie A. Simpson

University of Nebraska - Lincoln, msimpson2@unl.edu

Amy Schutz-Geschwender

LI-COR Biosciences

D. Michael Olive

LI-COR Biosciences

Follow this and additional works at: https://digitalcommons.unl.edu/biochemfacpub

Part of the Biochemistry, Biophysics, and Structural Biology Commons

Kovar, Joy L.; Simpson, Melanie A.; Schutz-Geschwender, Amy; and Olive, D. Michael, "A systematic approach to the development of fluorescent contrast agents for optical imaging of mouse cancer models" (2007). Biochemistry -- Faculty Publications. 9.

https://digitalcommons.unl.edu/biochemfacpub/9

This Article is brought to you for free and open access by the Biochemistry, Department of at DigitalCommons@University of Nebraska - Lincoln. It has been accepted for inclusion in Biochemistry -- Faculty Publications by an authorized administrator of DigitalCommons@University of Nebraska - Lincoln. 
Published in Analytical Biochemistry 367:1 (August 1, 2007), pp. 1-12; doi:10.1016/j.ab.2007.04.011

Copyright (C) 2007 Elsevier Inc. Used by permission. http://www.sciencedirect.com/science/journal/00032697

Submitted February 2, 2007; published online April 16, 2007.

REVIEW

\title{
A systematic approach to the development of fluorescent contrast agents for optical imaging of mouse cancer models
}

\author{
Joy L. Kovar ${ }^{\mathrm{a}}$, Melanie A. Simpson ${ }^{\mathrm{b}}$, Amy Schutz-Geschwender ${ }^{\mathrm{a}}$, and D. Michael Olive ${ }^{\mathrm{a}}$, \\ ${ }^{a}$ LI-COR Biosciences, Lincoln, NE 68504, USA \\ ${ }^{\mathrm{b}}$ Department of Biochemistry, University of Nebraska-Lincoln, Lincoln, NE 68508, USA \\ * Corresponding author. Fax: 402 467-0819; E-mail: molive@licor.com (D. M. Olive).
}

In the past decade, our increased elucidation of the molecular basis of cancer has led to the development of novel targeted strategies for specific inhibition of cancer signaling pathways that control growth, proliferation, apoptosis, and angiogenesis. Several monoclonal-antibody-based therapeutics and small-molecule drugs have received clearance for use as human therapeutics [1]. However, among these successes are many candidate drugs that have failed in clinical trials despite promising preclinical results [2].

The development of targeted therapeutics is expensive and time consuming. In their Critical Path Initiative, the United States Food and Drug Administration emphasized the need for more effective tools to facilitate the rapid development of improved cancer therapeutics. One such tool is the use of targeted molecular optical imaging probes or contrast agents to visualize the underlying processes in cancer.

Optical imaging, also known as molecular imaging, is a rapidly developing field of research aimed at noninvasively interrogating animals for disease progression, evaluating the effects of a drug, assessing the pharmacokinetic behavior of a drug, or identifying molecular biomarkers of disease. A prerequisite of molecular imaging is the development of specific, targeted imaging contrast agents to assess these biological processes. Several optical aids have shown great utility in animal studies, including bioluminescence, fluorescent proteins, and fluorochrome-labeled agents. However, only the latter have the advantage of being potentially relevant to human clinical applications.

The complexity of developing robust fluorochrome-labeled optical agents is often underestimated. Many studies describe the use of these agents, but guidelines for their development and testing are not readily available. The purpose of this review is to outline some of the considerations for developing and using fluorochrome-labeled optical contrast agents in animals. For simplicity, we have focused on the use of or- ganic fluorochromes as labeling agents. These types of probes are generally the most straightforward to develop and have the greatest potential for translation to human clinical use. Nanoparticles such as quantum dots, while useful for some animal studies, are hampered by clearance issues and toxicity and will not be specifically discussed. However, the principles described here are generally applicable to any fluorescent optical imaging agent.

\section{Principles of fluorescence imaging}

The use of fluorochrome-labeled optical agents such as labeled antibodies, receptor-binding ligands, small molecules, peptides, and activatable probes offers a flexible and direct imaging methodology. The fluorescent labels can be visualized by excitation with an appropriate light source and capture of the emitted photons with a chargecoupled device camera or other optical detector. Several commercially available imaging systems enable visualization of these probes in mice. These include systems from LI-COR Biosciences (http://www.licor.com/), CRI (http://www.cri-inc.com/), Kodak (http://www.kodak.com/), and Xenogen (http://www.xenogen.com/).

In fluorescent imaging, there are generally three parameters used to characterize the interaction of photons with tissues: light absorption, light scattering, and fluorescent emission. One of the most important considerations in optical imaging is maximizing the depth of tissue penetration. Absorption and scattering of light are largely a function of the wavelength of the excitation source [3]. Light is absorbed by endogenous chromophores found in living tissue, including hemoglobin, melanin, and lipid [3], [4], [5], [6], and [7]. In general, light absorption and scattering decrease with increasing wavelength. Below $\sim 700 \mathrm{~nm}$, these effects result in shallow penetration depths of only a few millimeters [3]. Thus, in 
the visible region of the spectrum, only superficial assessment of tissue features is possible. Above $900 \mathrm{~nm}$, water absorption can interfere with signal-to-background ratio. Because the absorption coefficient of tissue is considerably lower in the near infrared (NIR) region (700-900 nm), light can penetrate more deeply, to depths of several centimeters [3], [4], [5] and [6]. Fluorochromes with emissions in the NIR are not hindered by interfering autofluorescence, so they tend to yield the highest signal-to-background. The combination of increased depth of penetration and reduced autofluorescence makes NIR fluorochromes ideally suitable for optical imaging in small animals and potentially in humans also (Figure 1).

\section{Near infrared fluorochromes}

A key to enabling optical imaging has been the development of suitable NIR fluorochromes. Important criteria for effective optical imaging fluorochromes include excitation and emission maxima in the NIR between 700 and $900 \mathrm{~nm}$, high quantum yield [3], [4], [5], [6] and [7], chemical and optical stability, and suitable pharmacological properties including aqueous solubility, low nonspecific binding, rapid clearance of the free dye, and low toxicity. The dyes most commonly used for fluorescent optical imaging are listed in Table 1.

The cyanine dye Cy5.5 has been used frequently for in vivo imaging. The excitation/emission maxima $(675 \mathrm{~nm} / 695 \mathrm{~nm})$ are close to the NIR region, yielding acceptable signal-tobackground. Other dyes with excitation and emission maxima in this region include IRDye 700DX, IRDye 680, Alexa Fluor 700, and Alexa Fluor 680. Although excitation and emission wavelengths of these dyes are maximal in the more favorable red region, they do not give the optimal performance that can be achieved by moving farther into the NIR. Thus they are best used in situations when the highest sensitivity is not

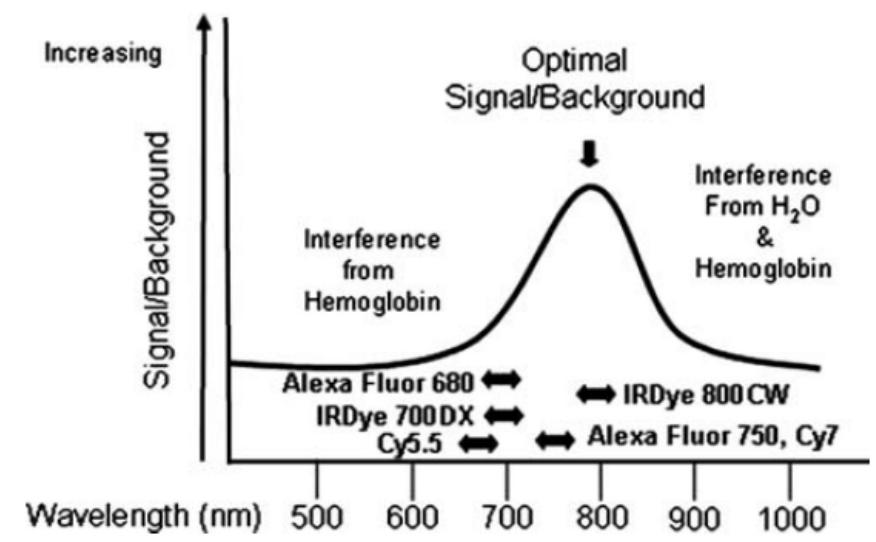

Figure 1. Schematic representation of the region of optimal signal-to-background ratio in tissue. Hemoglobin can interfere below $700 \mathrm{~nm}$ while water interferes above $900 \mathrm{~nm}$. The excitation and emission regions for several dyes commonly used in optical imaging are also indicated.
Table 1.

Excitation and emission maxima of fluorescent dyes commonly used for optical imaging

\begin{tabular}{lll}
\hline Fluorophore & Excitation $\max (\mathrm{nm})$ & Emission $\max (\mathrm{nm})$ \\
\hline Cy5.5 & 675 & 695 \\
Alexa Fluor 680 & 679 & 702 \\
IRDye 680 & 680 & 709 \\
Alexa Fluor 700 & 702 & 723 \\
IRDye 700DX & 689 & 700 \\
Alexa Fluor 750 & 749 & 775 \\
Cy7 & 749 & 775 \\
IRDye 800CW & 774 & 805 \\
\hline
\end{tabular}

required. However, the pthalocyanine dye IRDye 700DX has properties that may make it attractive for imaging. IRDye 700DX is considerably less sensitive to photobleaching than many organic fluorochromes; Peng et al. [8] have shown that IRDye700DX is 100 times more photostable than Alexa Fluor 680 and Cy5.5. In addition, members of the pthalocyanine dye class have been used for photodynamic therapy in the treatment of several types of cancer[9]. The photodynamic characteristics relevant to tumor therapy require prolonged exposure to the light source and therefore would not interfere with tumor biology during the short exposures used for imaging. Therefore, pthalocyanines have the potential to serve not only as imaging agents but also as therapeutics.

The most widely used dyes with true NIR character include IRDye 800CW, Cy7, and Alexa Fluor 750. The excitation/emission ranges for these dyes are shown schematically in Figure 1. In particular, IRDye $800 \mathrm{CW}$ has excitation/emission maxima of $774 \mathrm{~nm} / 789 \mathrm{~nm}$, which are centered at the optimal wavelength for in vivo imaging. This dye has been shown to be superior in performance to Cy5.5 with regard to signal-to-background [10].

\section{Targets and ligands}

Many targeted optical probes have been described in the literature. Targets include cell surface receptors, metabolic pathways, hormone receptors, apoptotic markers, and enzymatic activities [11]. High-affinity probes may be developed by rational investigation, combinatorial chemical synthesis, or phage display. An effective agent reaches the target at a sufficient concentration and/or is retained there for a sufficient length of time to be visible at the time of imaging. Obstacles such as rapid excretion, metabolism, nonspecific binding, and physical barriers to the agent reaching the target must be overcome for a targeted optical agent to function robustly.

Delivery barriers present the greatest obstacle but can be circumvented. One approach is to take advantage of normal cellular transport and endocytic processes by targeting surface receptors or transport pathways that internalize the optical agent. Growth factor receptors are an example in which the binding of a fluorochrome-labeled agent stimulates internal- 
ization via endocytosis. This has the added benefit of amplifying the fluorescent signal, since the fluorochrome will accumulate in the target cells. A second approach is to incorporate a peptide membrane translocation signal into the optical agent such that active transport of the imaging agent across the cell membrane results. Signal peptides such as the HIV tat peptide have been successfully used to transport nanoparticles into cells [12].

Nonspecific binding is another critical issue for noninvasive tumor imaging. In vivo, the inability to eliminate unbound ligand can cause low signal-to-background. In addition, nonspecific binding or retention of the optical probe will yield false positive results. Careful assessment of the optical agent clearance pattern and verification of specific signals by competition experiments can address this issue.

\section{Antibody conjugates}

Many of the first fluorochrome-conjugated targeted imaging agents were antibodies. For example, indocyanine-conjugated monoclonal antibodies against cells derived from a squamous cell carcinoma have been used to image A431 cell xenografts in nude mice [13]. Detection of the xenografts was sensitive and specific. Cy3-, Cy5-, and Cy5.5-conjugated monoclonal antibodies have been used to direct SSEA1 for detection of MH-15 teratocarcinoma xenografts [14]. In this study, fluorescence did concentrate in the tumor, but significant background from the conjugate was observed in the kidneys and bladder. The NIR dye, Cy5.5, appeared to yield the best signal-to-background. Finally, minibodies directed against the extra-domain $\mathrm{B}$ of fibronectin and conjugated to $\mathrm{Cy} 7$ have been used to successfully image atherosclerotic plaques in a mouse model [15].

Although antibody conjugates have been successfully used, they have several undesirable features, primarily due to the size of the antibody. Larger molecules, such as antibodies, can elicit an adverse immune response from the host animal, and their long half-life in the blood results in high background fluorescence and long clearance times [16] and [17]. In addition, large biomolecules are often taken up preferentially by the liver, precluding imaging of liver-proximal organs [18]. Finally, for the contrast agent to effectively penetrate to the target site, it must diffuse from the vasculature to the site of the pathology; larger molecules show very poor diffusion characteristics which may prevent them from reaching the target site [19].

\section{Tumor surface proteins}

Tumor surface proteins offer diverse possibilities for targeting of optical probes. An excellent example is a receptor-binding ligand. Growth factors are a popular choice for optical imaging agents because, in addition to high-affinity targeting, the ligand and its fluorescent label are often internalized by the normal endocytic pathway, amplifying the signal in the tumor cells. Fluorochrome-labeled epidermal growth factor (EGF) has been a versatile tumor imaging agent because the epidermal growth factor receptor (EGFR) is overexpressed on the surface of many types of tumor cells [20], [21], [22], [23], and [24]. In a study measuring the diffusion of small molecules across the extracellular space in rat brains, Thorne et al. [25] showed that EGF labeled with Oregon green 514 could be used as a reporter. Ke et al. [26] used Cy5.5-labeled EGF to target human breast tumor cells implanted in mice. The EGFCy5.5 accumulated specifically in the tumors and uptake was blocked by pretreatment of animals with C225 anti-EGFR monoclonal antibody (cetuximab).

Similarly, we have demonstrated the utility of EGF labeled with IRDye $800 \mathrm{CW}$ for analysis of orthotopic prostate tumors in mice [27] and [28]. IRDye 800CW EGF accumulated specifically in the tumors, and metastatic spread of the primary orthotopic tumor to the paraaortic lymph nodes was detected. EGF is known to stimulate tumor growth, and this is an important concern for its use as an imaging agent. Comparison of tumors excised from animals injected with labeled EGF only at the study endpoint to tumors excised from mice that had been injected at weekly intervals over a 6 week period demonstrated no stimulation of tumor growth by the fluorochrome-conjugated ligand used in this longitudinal study [27].

Endostatin, a $20-\mathrm{kDa}$ fragment of collagen XVIII, is a potent inhibitor of angiogenesis. Using Cy5.5-labeled endostatin, Citrin et al. [29] were able to demonstrate that the labeled optical agent bound specifically to tumor xenografts in C57BL mice, suggesting that the antiangiogenic effect of endostatin is due to its action directly on the tumor cells rather than to a general antiangiogenic effect. The Cy5.5-endostatin bound specifically to the tumor and the signal persisted for up to 7 days postintraperitoneal injection [29].

Apoptosis plays an important role in a number of disease pathologies, particularly cancer. One of the earliest markers of apoptosis is the externalization of phosphatidylserine. Annexin $\mathrm{V}$, a $36-\mathrm{kDa}$ protein, exhibits high affinity for phosphatidylserine and has been used to detect apoptosis in vivo. Petrovsky et al. [30] and Ntziachristos et al. [31] demonstrated the utility of Cy5.5-labeled annexin $\mathrm{V}$ for detection of apoptosis in a mouse tumor model. This marker may be useful in studying the antiproliferative effects of chemotherapeutic agents on a variety of cancers.

Somatostatin receptors and their ligands have been used as a targeting system for tumor imaging and radiotherapy of cancer for over 15 years. Radiolabeled synthetic analogues of somatostatin have been used to successfully image gastric or pancreatic tumors and small-cell lung cancer (SCLC) [32] and [33]. SCLC is a major cause of death in western countries. The substitution of fluorochrome-tagged somatostatin and several analogues has enabled imaging of human H69 SCLC tumor xenografts in mice using fiber-optic spectrofluorimetry. Thus, near-infrared-conjugated peptides may have significant clinical impact on tumor detection by endoscopy, mammography, and intraoperative imaging. 


\section{Peptides and small molecules}

Because of their small size, convenience of handling, and attractive pharmacokinetic properties, peptides are useful agents for in vivo imaging. Peptides targeting integrins, a family of cell surface receptors that broadly regulate tumor growth, metastasis, and angiogenesis, have been successful agents for imaging neovascular density [34], [35], [36], [37], [38], [39], [40], and [41]. Chen et al. [37] and Achilefu et al. [41] used an NIR peptide conjugate, arginine-glycine-aspartic acid (RGD), targeting $\alpha_{\mathrm{v}} \beta_{3}$ integrin, to detect and image tumor xenografts and to monitor angiogenesis. Tumor uptake of the Cy5.5 RGD peptide was specific and could be blocked by preinjection with unlabeled RGD. Houston et al. [42] used an RGD peptide doubly labeled with ${ }^{111}$ indium and IRDye $800 \mathrm{CW}$ to directly compare NIR optical imaging with scintigraphy. The authors found the signal-to-background ratio significantly higher for IRDye $800 \mathrm{CW}$ than for the radioactive label.

In general, small molecules and peptide imaging agents clear the system quickly, translating to a reduction in fluorescent background when imaging. In all cases described above, the agents cleared through the kidneys without pooling in the liver. The small size also greatly reduces the possibility of an adverse immune response. Finally, fluorochromelabeled small molecules and peptides penetrate to the target efficiently because of their increased ability to diffuse from the vasculature.

\section{Activatable probes}

The last category of fluorescent agents, activatable probes or "molecular beacons" [43] and [44], specifically yield a fluorescent signal only when activated by an enzyme target. Most activatable probes are protease substrates. Protease levels are elevated in the extracellular space of many tumors, where they play roles in invasion and metastasis [45], [46], [47], [48], and [49] and present a physically accessible target. Typically, these probes contain multiple NIR fluorochromes coupled to peptide sequences that can be cleaved by the protease. The proximity of the fluorochromes to each other results in quenching that is relieved upon cleavage by the target protease to generate a fluorescent signal. Use of fluorochrome/quencher pairs separated by the peptide target sequence has also been reported.

Proteases that have been targeted by activatable probes include cathepsins, matrix metalloproteinases (MMPs), prostate-specific antigen, thrombin, caspase-3, and interleukin-1 $\beta$ converting enzyme [50]. An example of the signal sensitivity that can be achieved using these agents is the visualization of MMP-2 activity [50], [51], and [52]. In vitro, the authors observed an $850 \%$ increase in NIR fluorescence intensity when the probe was cleaved and specific activation could be blocked by MMP-2 inhibitors. MMP-2-positive human fibrosarcomas were visualized and differentiated from MMP-2-negative mammary adenocarcinomas using this probe.

\section{Developing an optical imaging agent}

Below, we will discuss some of the critical parameters involved in developing, validating, and using an optical imaging agent. We present an overview of the process as it applies to tumor imaging, using as an example the IRDye 800CW EGF imaging agent that we recently developed [27] and [28]. Again, although we use this agent as an example, the principles described will be applicable to any dye-conjugate optical agent.

\section{Conjugating probes with NIR dyes}

Development of an optical targeting agent begins with covalent attachment of an NIR dye to the targeting compound. Many dyes are available with an $N$-hydroxysuccinimidyl (NHS) ester, which is activated for simple one-step coupling to free amines. NHS esterified NIR dyes may be purchased in bulk or in prepackaged labeling kits. Methods for removal of unreacted dye may include HPLC, FPLC, or dialysis. Purification will be dictated by the molecular weight and chemical properties of the conjugates.

For in vivo imaging applications, the dye/protein ratio of the conjugate may affect biological or biochemical activity of the protein, signal-to-background ratio, clearance, and biodistribution [52]. The optimal ratio of coupling is unique to each targeting agent. For example, Ntziachristos et al. [31] found that annexin $\mathrm{V}$ labeled with Cy5.5 at a dye/protein ratio of 1 retained its ability to bind phosphatidylserine on the surface of cells induced for apoptosis, while the same molecule labeled at a dye/protein ratio of 2.4 had lost its binding capability.

If the optical imaging agent is based on a commercially available reagent such as an antibody or receptor ligand, differences in preparation and purification may impact performance. We conjugated IRDye $800 \mathrm{CW}$ to human recombinant EGF from five different commercial sources, at equivalent dye/protein ratios, and evaluated relative signal intensity by In-Cell Western (ICW) [28]. As shown in Figure 2, there were considerable differences in the amounts of EGF bound to the cells. Variations in signal strength measured in this fashion have the potential to predict probe performance in vivo as we have demonstrated [28].

\section{Testing the performance and specificity of an optical im- aging agent in vitro}

Validation of targeting agent efficacy and specificity in vitro is an important prelude to animal studies. Specificity can be demonstrated on cells in culture or in suspension by blocking the target with an antibody or by competition with the unlabeled agent. In targeting somatostatin receptors, Becker et al. [53] used a flow cytometric assay to quantify binding of the agent. As mentioned above, Ntziachristos et al. [31] used whole-cell competition assays to demonstrate both probe specificity and binding affinity. Another group used a radioactive 


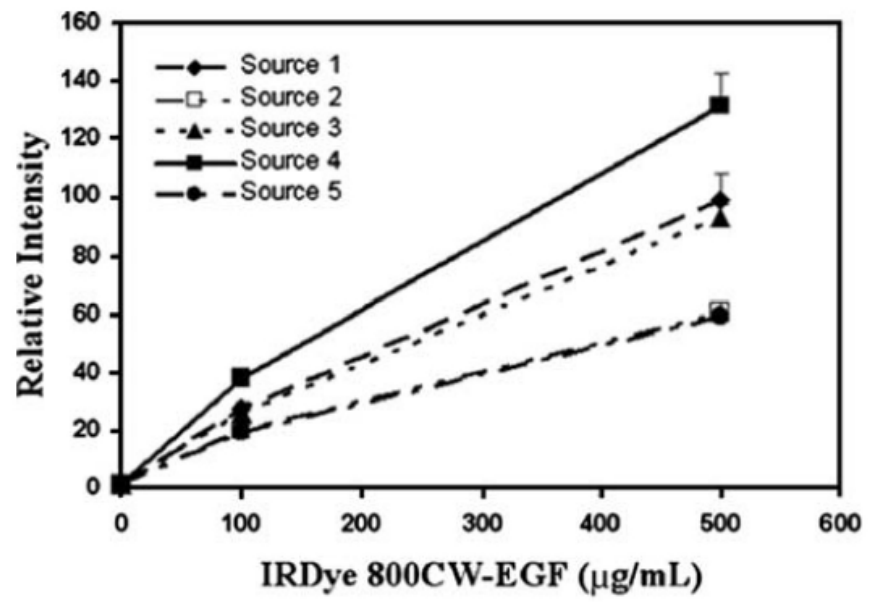

Figure 2. Binding activity of recombinant EGF from different commercial sources. EGF from five sources was conjugated to IRDye $800 \mathrm{CW}$ at similar dye/protein ratios and each was evaluated for its ability to bind confluent A431 monolayers by In-Cell Western as we have previously described [27].

displacement assay [54]. ${ }^{125}$ I-labeled echistatin, an integrinbinding ligand, was added to integrin-expressing cell cultures and allowed to bind. The degree of displacement of the radioactive echistatin by Cy7-labeled RGD peptide was used as a measure of specificity and binding affinity.

We have used the ICW or cytoblot to evaluate IRDye $800 \mathrm{CW}$ EGF for binding and specificity prior to actual testing in mice [27] and [55]. In this assay, PC3M-LN4 and 22Rv1 human prostate adenocarcinoma cells were cultured in microtiter plates and treated with serial dilutions of labeled EGF (Figure 3A) to verify high affinity binding of EGFR-targeted dye relative to the low binding of free dye alone (Figure 3B). Specificity was then established in two ways: by blocking access of EGF to its receptor with the anti-EGFR monoclonal antibody C225 (also known as cetuximab or Erbitux, Figure 3C) and by competition with unlabeled EGF (Figure 3D). Fluorescence of the microplate was quantified by NIR imaging, and a DNA stain was used to normalize variations in cell number.

Characterization of the targeting agent in a cell-based assay can simplify probe development. While success in a cellbased assay format does not guarantee performance in vivo, failure in this assay is generally predictive of failure in the animal. In addition, the competition assays developed may subsequently be useful for demonstrating specificity in animal experiments.

\section{Animal care and use}

All research animals must be handled according to protocols that comply with the animal care and use regulations of the country and institution where the research will be performed.
In the United States, these regulations are described in a document compiled by the National Institutes of Health Organization for Lab Animal Welfare, available at http://grants.nih.gov/grants/olaw/GuideBook.pdf.

\section{Considerations for tumor model selection}

An ideal tumor model system exhibits minimal background interference. Although much of the autofluorescence in the animal is ameliorated by imaging at NIR wavelengths, some anatomic regions inherently maintain higher fluorescent signals. For example, natural fluorescence from compounds in the animal's diet accumulates and can be visualized in the abdominal cavity. Organs involved in clearance of the dye, such as the liver and kidney, may also accumulate signal. Tumors arising in areas remote from these organs are detected with less ambiguity and higher sensitivity. In the case of subcutaneous xenografts, the placement of transplanted tissue in the flank, shoulder, or leg of the animal can minimize these interfering factors.

The model system selected will depend on the aims of the study. Transgenic, chemically induced, and spontaneously arising mouse models that recapitulate many aspects of the genesis, progression, and clinical course of human cancers are available. The National Cancer Institute of the United States has organized a Cancer Models Database (caMOD) to facilitate identification of appropriate models for cancer experimental design (http://0-cancermodels.nci.nih.gov.library.unl. edu:80/camod/login.do;jsessionid=D8B27DC9B409DA8CC3 7CE04150EBAABB).

Three strains of immunodeficient mice are commonly used in tumorigenesis and metastasis research with human cell lines: nude, SCID, and Rag1. The nude mouse (athymic; nu/ nu) has a disruption in the Foxn 1 gene, resulting in an absent or deteriorated thymus gland, diminished $\mathrm{T}$ cell numbers, and a severely impaired cellular immune system [56]. The resultant hairless phenotype also makes the nude mouse ideal for optical imaging, since animal hair blocks and scatters light. Over time, these animals may regain partial cellular immune function so nude mice may not be the best host for longer-term studies of tumor biology. SCID (severe combined immunodeficiency) mice lack both mature $\mathrm{T}$ and $\mathrm{B}$ lymphocytes [57] and are an effective alternative to nude mice in cases where the partial immune system of the nude mouse presents a problem. The Rag1 mouse also lacks $\mathrm{T}$ and $\mathrm{B}$ lymphocytes and is not able to undergo $\mathrm{V}(\mathrm{D}) \mathrm{J}$ recombination. Thus, it fails to produce T-cell receptors and immunoglobulin molecules for antigen identification [58], [59] and [60]. All three mouse models bear phenotypic and background strain characteristics that may impact a research project.

Immunocompromised mice require specific-pathogen-free handling to avoid introducing infections. Institutional training is obligatory and includes instruction in the use of infection barriers, sterilized food, water, and bedding, disinfected imaging surfaces, gloved handling, and aseptic technique. 

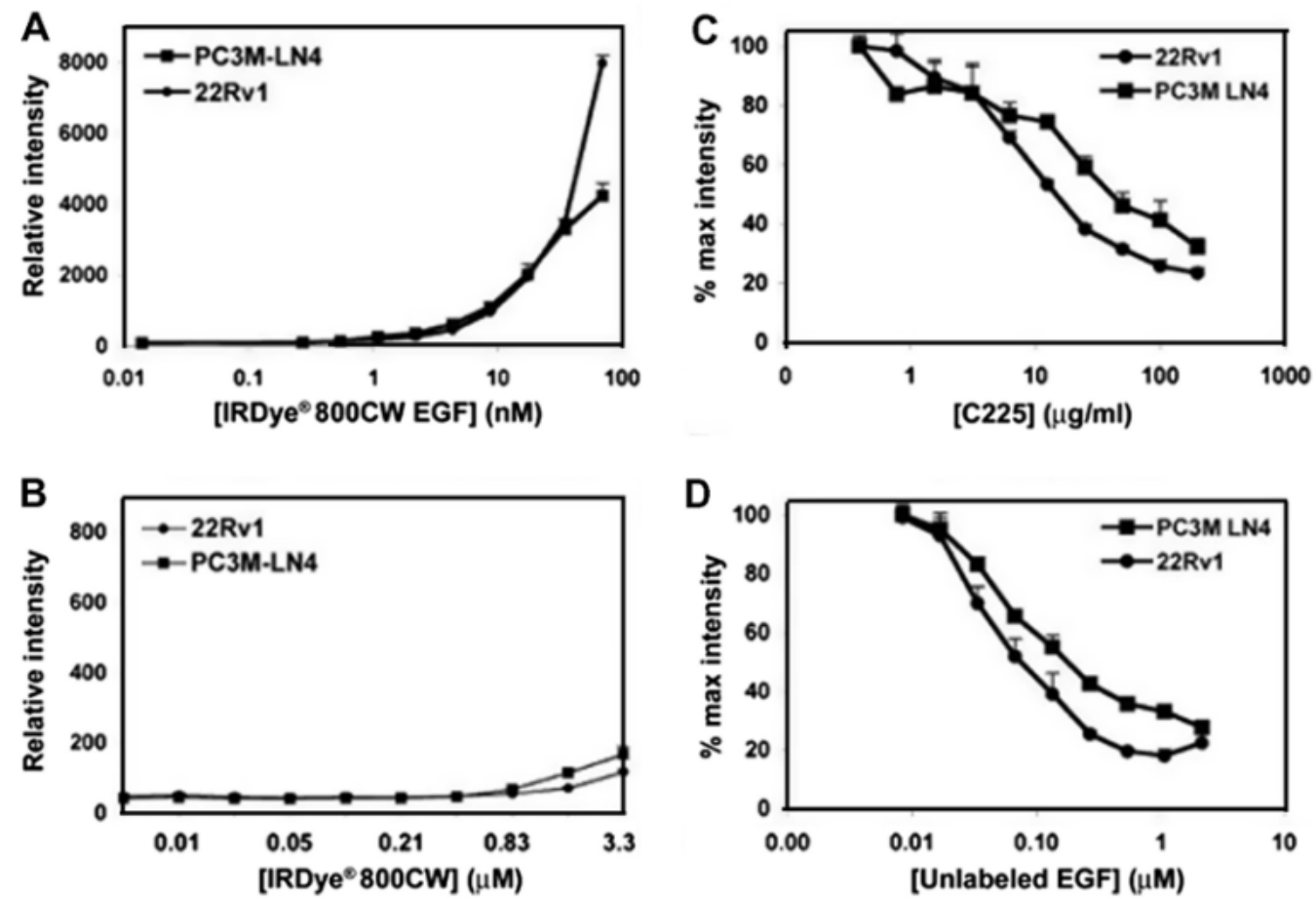

Figure 3. Binding specificity of IRDye 800CW EGF for cultured PC3M-LN4 and 22Rv1 cells. Monolayer cells in 96-well microplates were incubated with increasing concentrations of IRDye 800CW EGF (A) or unconjugated nonreactive IRDye 800CW (B) and normalized with TOPRO-3 staining. To demonstrate EGF receptor-targeting specificity, cells were incubated with $70 \mathrm{nM}$ IRDye $800 \mathrm{CW}$ EGF in the presence of increasing concentrations of either C225 blocking antibody (C) or unlabeled EGF (D). The 800-nm signal, normalized to the 700-nm control, is plotted as the mean \pm SD of three replicate wells [27]. This figure is reproduced with permission from the American Journal of Pathology.

\section{Reducing optical interference for tumor imaging}

Chlorophyll, which is often present in animal chow, absorbs at 655 and $411 \mathrm{~nm}$ and fluoresces at $673 \mathrm{~nm}$, producing strong signal in the abdominal cavity. For optimal fluorescent imaging performance, purified food formulations that do not contain plant products may be used. Fasting of the animal prior to imaging has been used in some studies and requires prior approval from the institutional committee governing animal care.

The hairless phenotype of the nude mouse makes it an ideal choice for NIR optical imaging, but this model may not always be appropriate for the research objectives. Thus, hair removal in the imaging region may be important for optimal signal detection. Animal hair interferes with imaging by blocking, absorbing, and scattering light. We evaluated this by implanting a tube containing IRDye $800 \mathrm{CW}$ in the chest cavity of a deceased SCID mouse and imaging the animal before and after shaving. Following shaving, fluorescent signal increased by $>50 \%$ (data not shown). An additional $12 \%$ signal was detected when the animal was treated with a depilatory cream (Nair, Church and Dwight Co., Inc.) presumably due to the removal of hair stubble.

\section{Establishing tumors in the animal}

For assays of tumorigenic and metastatic potential using cultured human cells, cells or tissue may be implanted in animals subcutaneously, intravenously, intraperitonally, or orthotopically (i.e., prostate cells implanted in mouse prostate). These assays are called xenografts, since they involve transplantation of cells, tissue, or organs from one species to another.

Depending on the aggressiveness of the cell line, we have established subcutaneous xenografts in mice by injection of $0.5-1 \times 10^{6}$ cells in $\approx 100 \mu \mathrm{L}$ cell suspension. Tumors become palpable within 7-10 days. Orthotopic injections require fewer cells (we have used $1 \times 10^{5}$ cells) and reduced injection volume $(10 \mu \mathrm{L})$, as the prostate is small. Tumors form in 2-3 weeks and metastasize within $\approx 6$ weeks [27] and [28].

\section{Probe dosage and administration}

Tumor type may dictate the optical imaging agent selected and its optimal parameters for use. For example, A431 epidermoid carcinoma cells express EGFR at a much higher level than normal cells. However, HeLa ovarian carcinoma cells have low expression of EGFR. If IRDye 800CW EGF is used as an optical probe for both of these cell types, binding of the labeled ligand would be expected to vary dramatically.

An optimal dosage of the imaging agent will afford the best signal-to-background, clearance, and imaging results. Excessively high doses will clear poorly, while a low dose may not saturate tumor uptake. Figure 4 illustrates a dose response to increasing concentrations of an optical agent. Although background increases with the amount of probe administered, 

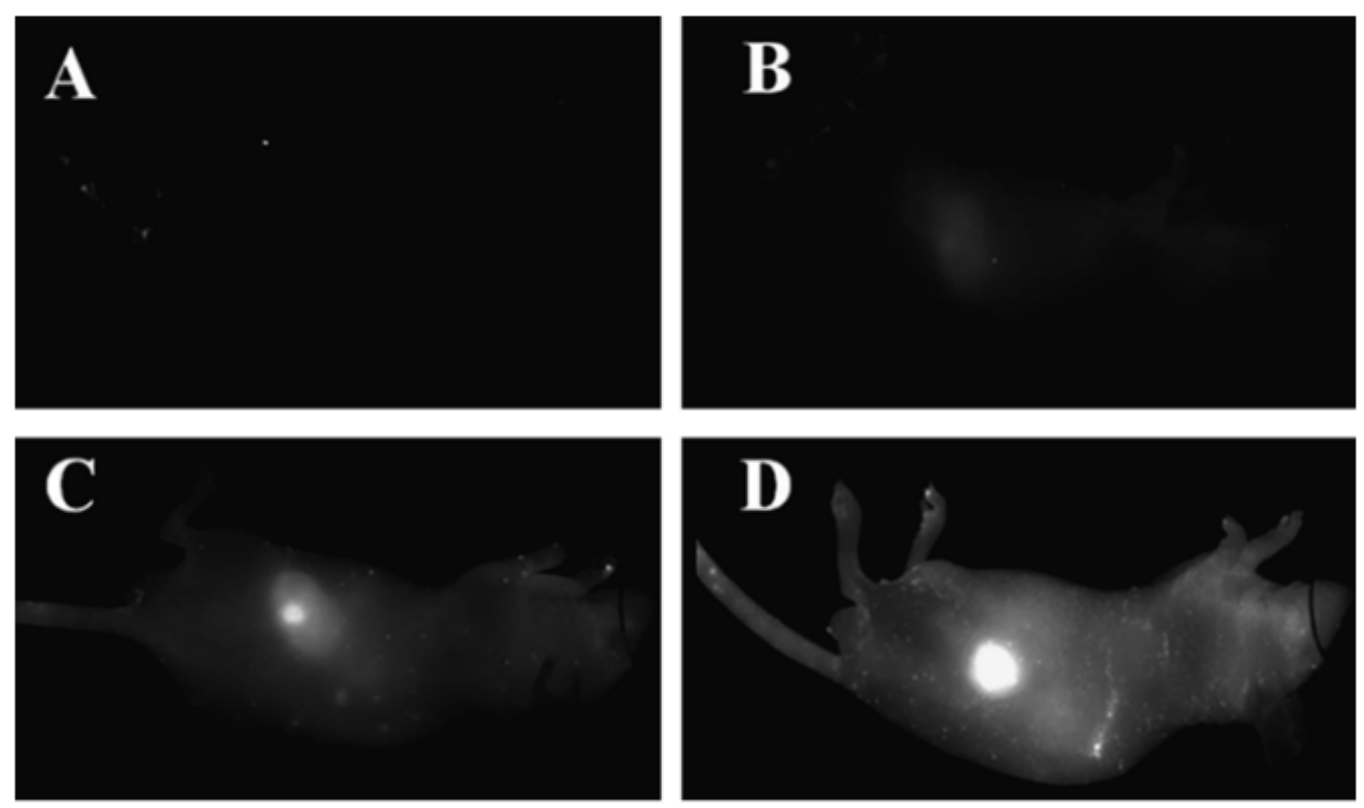

Figure 4. Dose response for an IRDye $800 \mathrm{CW}$-conjugated optical imaging agent targeting tumors in nude mice. Animals were injected with $1 \times$ phosphate-buffered saline as a negative control (A), or with $2.5 \mathrm{nmol}$ (B), $5.0 \mathrm{nmol}$ (C), and $10 \mathrm{nmol}$ (D) of a tumor-targeted IRDye $800 \mathrm{CW}$ conjugate. Images were acquired $24 \mathrm{~h}$ postinjection.

the signal is also greater at the highest dose. The quantified signal within the tumor, normalized to the mean background in several irrelevant surrounding regions, allowed us to determine that the optimal specific signal occurred at the two highest doses.

The route of targeting agent administration can affect its specific uptake and nonspecific clearance. Intravenous injection via the tail vein or supraorbital cavity leads to rapid systemic dispersion (Figure 5B). This method is appropriate for targeted contrast agents that bind a ubiquitous surface receptor present at a greater concentration on tumor cells. Uptake by the tumor cells is within the time window of agent clearance and potential background from prolonged exposure to the probe is minimized. Performance of an agent that functions by incorporation into bone, however, may be enhanced by intraperitoneal injections, which prolong exposure through slower dispersion (Figure 5A).

\section{Evaluation of dye and optical agent clearance}

Performing initial imaging time courses following injection of the chosen targeting agent will establish the optimal time point for sensitive tumor analysis. First, the time course analysis begins with the unconjugated fluorochrome chosen for optical imaging, which should not be appreciably retained in the animal. An example of measurement of the clearance of IRDye $800 \mathrm{CW}$ is shown in Figure 6. Other dyes may have different clearance characteristics. Second, a time course of agent clearance from non-tumor-bearing control animals using the intended dose for tumor imaging will yield a blueprint for whole-body nonspecific background to assist interpretation of tumor images. Figure 7 shows the results of a clearance experiment with IRDye 800CW EGF in a tumor-negative mouse.

Finally, once it has been determined that the probe does not accumulate nonspecifically, the time course is repeated
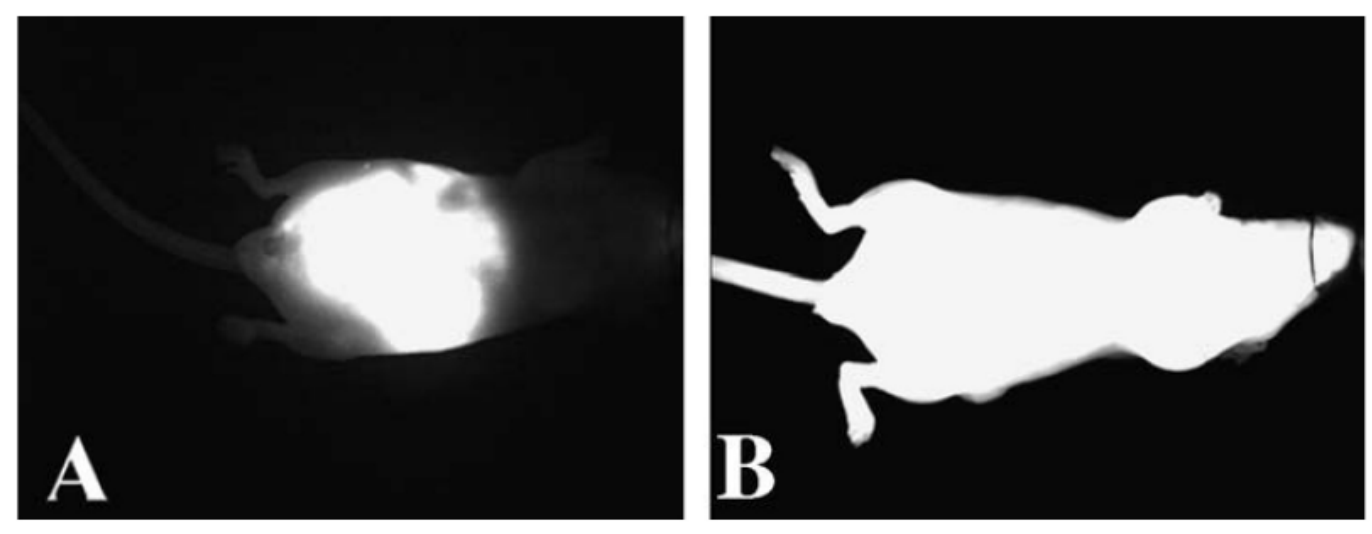

Figure 5. Impact of administration site on optical imaging agent dispersion in mice. Images were acquired approximately 15 min following intraperitoneal (A) or intravenous (B) injection of equivalent amounts of an optical imaging agent into a nude mouse. 

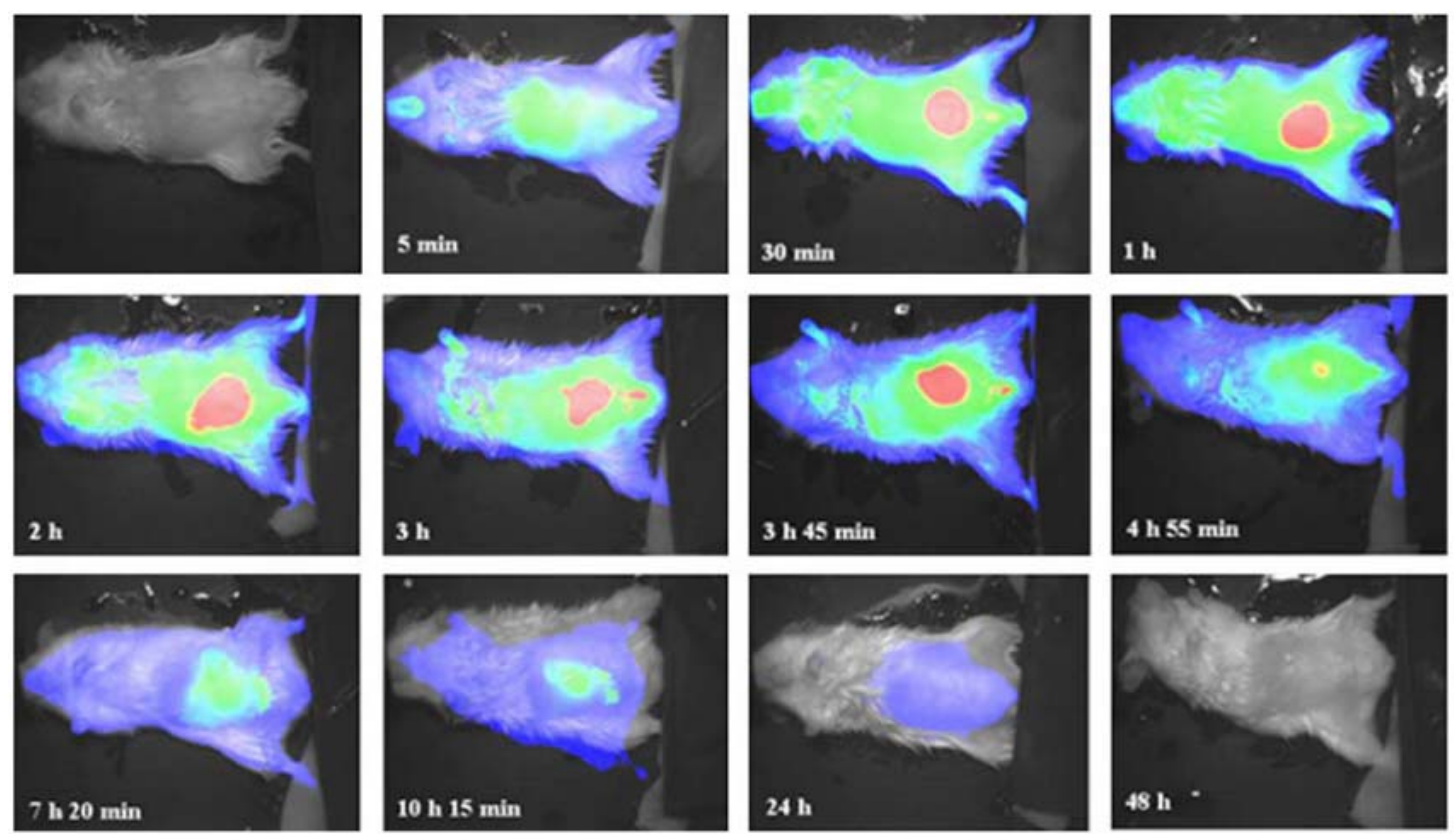

Figure 6. Clearance kinetics of unconjugated IRDye 800CW. A SCID mouse was injected with 1 nmol of IRDye $800 \mathrm{CW}$ intravenously and monitored over time for complete clearance of the dye. Imaging times postinjection are indicated on each individual image. Pseudocolored fluorescence is superimposed on the white light image of the mouse to illustrate rapid dispersion of the dye followed by complete clearance.
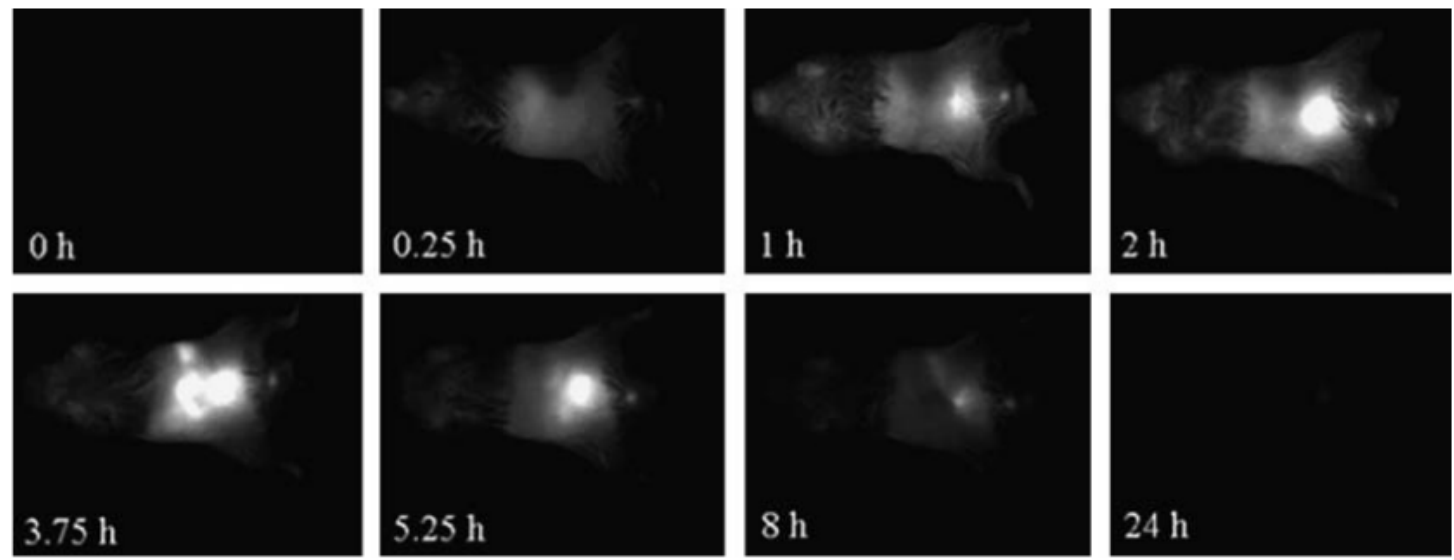

Figure 7. Time course for clearance of IRDye $800 \mathrm{CW}$ EGF from a non-tumor-bearing mouse. A SCID mouse was injected with 1 nmol of the EGF-conjugated optical agent intravenously and imaged at the indicated time points over a 24-h period. Analysis of the abdominal region showed that $>90 \%$ of the fluorescence disappeared in $24 \mathrm{~h}$, and by $48 \mathrm{~h}$ (not shown) the probe had cleared completely.

with tumor-bearing animals to determine the imaging time at which the signal-to-background is greatest in the tumor. For IRDye 800CW EGF, mice bearing PC3M-LN4 subcutaneous xenografts were imaged over a 3-day period. By $24 \mathrm{~h}$, most of the initial fluorescence was gone from the nontumor areas (Figure 8). However, signal-to-background continued to increase beyond this time point. Optimizing the time of imaging maximizes sensitivity for challenging applications such as detecting metastatic spread of a tumor.

\section{Confirming probe specificity in vivo}

Clearance studies and optimization of timing will minimize nonspecific fluorescence, but imaging artifacts may be misin- terpreted nonetheless. For example, an apparent tumor detected in the liver upon targeting with an antibody probe that pooled in the liver should be confirmed by a competition test. One method is to preinject tumor-bearing animals with an excess (for example, 100-fold) of the unlabeled form of the optical agent. The labeled agent is injected shortly thereafter. Probe specificity is reflected as a decrease in the total fluorescence signal in animals that were preinjected with the unlabeled agent. Specificity of Cy5.5-labeled EGF was demonstrated in this way by Ke et al. [26]. Even if differential signal is not readily detected in intact animals, imaging analysis of excised whole and sectioned tumors may reveal the competition.

We used this approach to assess specificity of IRDye $800 \mathrm{CW}$ EGF imaging in prostate tumors [27]. Mice bearing 

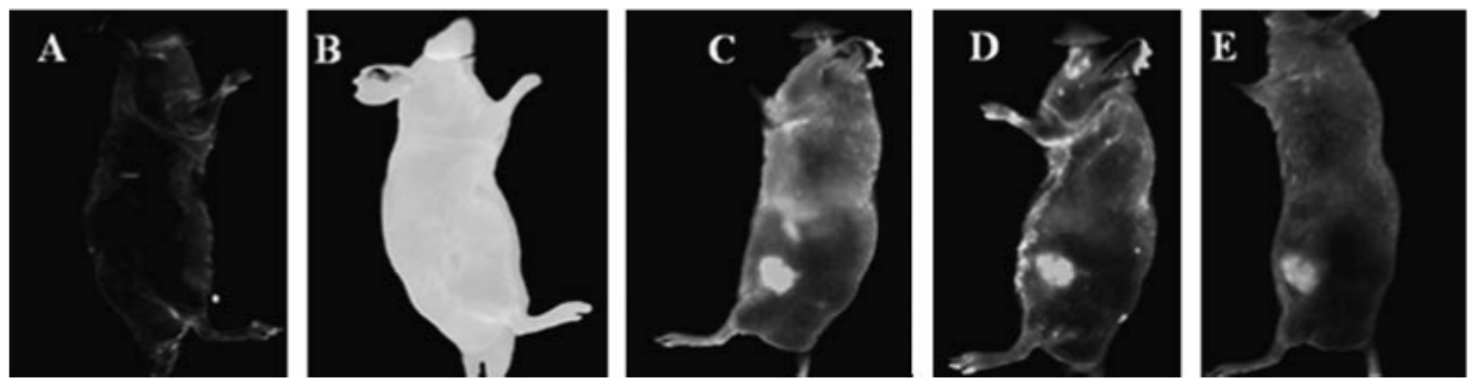

Figure 8. Time course for accumulation of IRDye 800CW EGF in a subcutaneous tumor. Images of a nude mouse were collected prior to injection (A) or at $20 \mathrm{~min}(\mathrm{~B}), 24 \mathrm{~h}(\mathrm{C}), 48 \mathrm{~h}(\mathrm{D})$, and $72 \mathrm{~h}$ (E) following intravenous injection of the animal with $1 \mathrm{nmol}$ of IRDye $800 \mathrm{CW}$ EGF.

either PC3M-LN4 subcutaneous or orthotopic tumors were injected with IRDye 800CW EGF; some animals were preinjected with C225 anti-EGFR monoclonal antibody. When we injected tumor-bearing animals with the probe and subsequently performed fluorescence imaging of tumor sections, IRDye $800 \mathrm{CW}$ EGF was clearly visible not only in the primary tumors but also in lymph nodes extracted from the animals (Figure 9). Tumor-bearing animals that were preinjected with C225 exhibited a 33-49\% decrease in fluorescent signal, indicating that binding of the labeled ligand was specific for EGFR.

An alternative approach to demonstrating specific signal is to quantify targeting agent uptake by both tumor and nontumor tissue. For examining integrin-binding agents, Becker et al. [53] used an RGD peptide doubly labeled with ${ }^{125} \mathrm{I}$ and an indocarbocyanine dye. Radioactive content of the tumor,

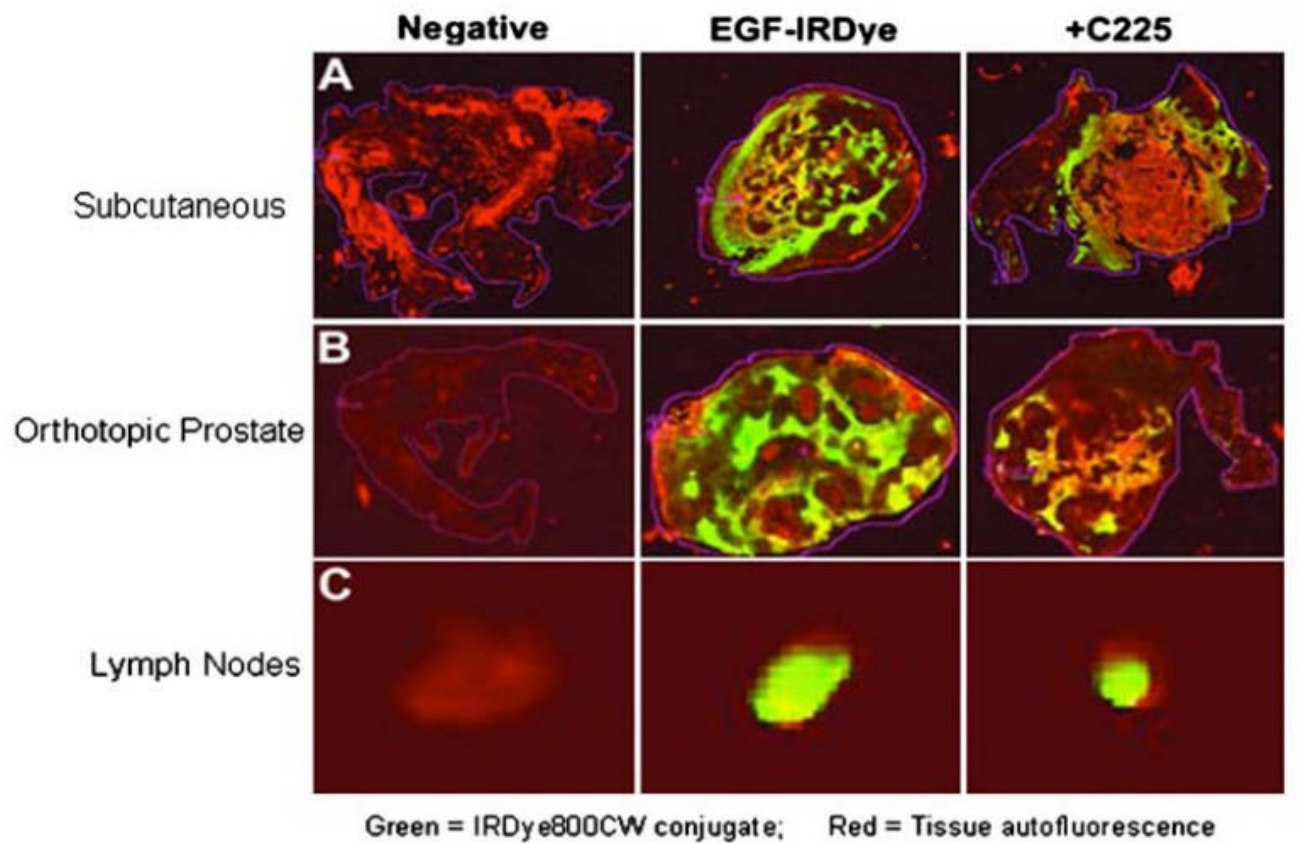

Fluorescence signal ${ }^{*} / \mathrm{mm} 2$ by tissue

\begin{tabular}{|l|r|r|r|}
\hline \multicolumn{1}{|c|}{ Treatment } & Subcutaneous & Orthotopic & \multicolumn{1}{c|}{ Nodes } \\
\hline Vehicle only & 0.01 & 0.14 & 0.01 \\
\hline IRDye 800CWWGF & 0.69 & 1 & 1.15 \\
\hline C225+IRDye 800CWEGF & 0.38 & 0.52 & 0.76 \\
\hline Percentage Signal Blocked & 45.7 & 49.0 & 33.7 \\
\hline
\end{tabular}

"Integrated intensity in the $800 \mathrm{~nm}$ channel normalized to unit area of the section $\alpha$ tissue sample

Figure 9. Demonstration of specific tumor targeting in vivo for the IRDye 800CW EGF optical imaging agent. Tumors and lymph nodes were excised from animals bearing either subcutaneous (A) or orthotopic (B) prostate tumors, as indicated, injected intravenously with IRDye 800CW EGF or preinjected with C225 anti-EGFR monoclonal antibody prior to dosing with IRDye 800CW EGF. The corresponding table presents IRDye 800CW EGF fluorescence signal per area tissue for vehicle control, optical agent only, and C225 competition for each tumor type (subcutaneous and orthotopic) and lymph nodes from the orthotopic tumor model (C). 
heart, liver, kidneys, and brain was quantified following imaging of the tumor. Thus, the authors were able to express the uptake of the probe as the percentage of injected dose per gram of tissue. This approach may also be useful for characterization of metabolic probes, for which high doses of unlabeled competitor may be toxic.

\section{Conclusions}

Fluorochrome-labeled molecular probes are valuable tools for noninvasive longitudinal study of tumorigenesis and metastasis, preclinical studies of the effects of therapeutic agents, and pharmacokinetic and pharmacodynamic studies of drug-target interactions. Because of this, these probes have significant potential for translation to human clinical use.

Several applications may expand the clinical utility of fluorochrome-labeled probes. For example, accurate definition of tumor margins is crucial to the therapeutic outcome of many surgical oncology procedures. A multimodal imaging agent consisting of a magnetic iron oxide nanoparticle and Cy5.5 has been used as a preoperative nuclear magnetic resonance contrast agent and intraoperative optical probe to define the tumor margins in a rat gliosarcoma model [61]. Similar intraoperative imaging technology is being developed in the laboratory of Frangioni [62]. These procedures would allow a surgeon to identify and locate the tumor mass by MRI and subsequently remove the tumor accurately with visual guidance from an intraoperative near-infrared fluorescent imager.

Photodynamic therapy is an application that has been used in oncology for over 2 decades [9]. A photosensitizing agent delivered to malignant tissue is exposed to light, generating cytotoxic singlet oxygen. The result is cell death through the induction of apoptosis, microvascular damage, and antitumor immune response. The major class of dyes used for this approach is phthalocyanines such as IRDye 700DX [8]. NIR dyes conjugated to antitumor therapeutics such as Erbitux (anti-EGFR monoclonal antibody) may have similar clinical appeal for simultaneous treatment and monitoring of anticancer therapy [63].

Imaging based on expression of luciferase or a fluorescent protein such as GFP has facilitated examination of intracellular signaling events in vivo. Hybrid gene constructs in which either the luciferase or the GFP gene is placed under control of an inducible promoter responsive to a signaling pathway of interest have been used to directly assess the effects of antitumor agents on the gene regulation in vivo. A similar reporter system that directly images $\beta$-galactosidase activity on a farred substrate has been recently reported [64]. This fluorescent reporter system could provide a means for creating hybrid expression units to examine in vivo gene expression and regulation of a number of important pathways in cancer.

NIR-based imaging instrument technologies designed for human clinical use are in various stages of development [62], [65] and [66]. Combined with new NIR-labeled biomarkers, these will expand the clinical options available for can- cer management in the near future. Several excellent reviews describe the use of targeted markers in animal studies [7] and [67].

In this review we have discussed the basic validation of fluorochrome-labeled molecular probes. Although near-infrared optical excitation sources provide deeper tissue penetration, they are not great enough to provide unlimited application for human clinical use. Near-infrared imaging agents may be limited to accessible tissues such as breast tumors or to intraoperative applications, endoscopy, and photodynamic therapy. However, these applications represent significant benefits for research, diagnosis, and treatment. Continued technological innovation in imaging instrumentation, biomarker discovery, and labeling chemistries will foster the clinical use of fluorescent optical imaging.

\section{References}

[1] J. Dancey and E.A. Sausville, Issues and progress for protein kinase inhibitors for cancer treatment, Nat. Rev. Drug Discov. 2 (2003), pp. 296-313.

[2] J.W. Park, R.S. Kerbel, G.J. Kelloff, J.C. Barrett, B.A. Chabner, D.R. Parkinson, J. Peck, R.W. Ruddon, C.C. Sigman and D.J. Slamon, Rationale for biomarkers and surrogate endpoints in mechanism driven oncology drug development, Clin. Cancer Res. 10 (2004), pp. 3885-3896.

[3] K. Licha, Contrast agents for optical imaging, Topics Curr. Chem. 222 (2002), pp. 1-29.

[4] B.J. Tromberg, N. Shah, R. Lanning, A. Cerussi, J. Espinoza, T. Pham, L. Svaasand and J. Butler, Non-invasive in vivo characterization of breast tumors using photon migration spectroscopy, Neoplasia 2 (2000), pp. 26-40.

[5] D.J. Hawrysz and E.M. Sevick-Muraca, Developments toward diagnostic breast cancer imaging using near-infrared optical measurements and fluorescent contrast agents, Neoplasia 2 (2000), pp. 388-417.

[6] M. Gurfinkel, S. Ke, X. Wen, C. Li and E.M. Sevick-Muraca, Near-infrared fluorescence optical imaging and tomography, Disease Markers 19 (2004), pp. 107-121.

[7] J.V. Frangioni, In vivo near-infrared fluorescence imaging, Curr. Opinion Chem. Biol. 7 (2003), pp. 626-634.

[8] X. Peng, D.R. Draney, W.M. Volcheck, G.R. Bashford, D.T. Lamb, D.L. Grone, Y. Zhang and C.M. Johnson, Phthalocyanine dye as an extremely photostable and highly fluorescent near-infrared labeling reagent, Proc. SPIE 6097 (2006), pp. 113-124.

[9] P. Harrod-Kim, Tumor ablation with photodynamic therapy: Introduction to mechanism and clinical applications, J. Vascular Interventional Radiol. 17 (2006), pp. 1441-1448.

[10] K.E. Adams, S. Ke, S. Kwon, F. Liang, Z. Fan, Y. Lu, K. Hirschi, M.E. Mawad, M.A. Barry and E.M. Sevick-Muraca, Comparison of visible and near-infrared wavelength fluorescent dyes for molecular imaging of cancer, J. Biomed. Opt. 12 (2007) 024017-1-024017-9.

[11] G.J. Kelloff, K.A. Krohn, S.M. Larson, R. Weissleder, D.A. Mankoff, J.M. Hoffman, J.M. Link, K.Z. Guyton, W.C. Eckelman, H.I. Scher, J. O'Shaughnessy, B.D. Cheson, C.C. Sig- 
man, J.L. Tatum, G.Q. Mills, D.C. Sullivan and J. Woodcock, The progress and promise of molecular imaging probes in oncologic drug development, Clin. Cancer Res. 11 (2005), pp. 79677985.

[12] M. Lewin, N. Carlesso, C.H. Tun, X.W. Tang, D. Cory, D.T. Scadden and R. Weissleder, Tat peptide-derivatized magnetic nanoparticles allow in vivo tracking and recovery of progenitor cells, Nat. Biotechnol. 18 (2000), pp. 410-414.

[13] S. Folli, P. Westermann, D. Braichotte, A. Pelegrin, G. Wagnieres, H. van den Bergh and J.P. Mach, Antibody-indocyanin conjugates for immunophotodetection of human squamous cell carcinoma in nude mice, Cancer Res. 54 (1994), pp. 26432649.

[14] B. Ballou, G.W. Fischer, A.S. Waggoner, D.L. Farkas, J.M. Reiland, R. Jaffe, R.B. Mujumdar, S.R. Mujumdar and T.R. Hakala, Tumor labeling in vivo using cyanine-conjugated monoclonal antibodies, Cancer Immunol. Immunother. 41 (1995), pp. 257-263.

[15] C.M. Matter, P.K. Schuler, P. Alessi, P. Meier, R. Ricci, D. Zhang, C. Halin, P. Castellani, L. Zardi, C.K. Hofer, M. Montani, D. Neri and T.F. Luscher, Molecular imaging of atherosclerotic plaques using a human antibody against the extra-domain B of fibronectin, Circulation Res. 95 (2004), pp. 1225-1233.

[16] S.J. Goldsmith, Receptor imaging: competitive or complementary to antibody imaging?, Semin. Nucl. Med. 27 (1997), pp. 85-93.

[17] S. Achilefu, J.E. Bugaj, R.B. Dorshow, H.N. Jimenez and R. Rajagopalan, New approach to optical imaging of tumors, Proc. SPIE 4259 (2001), pp. 110-114.

[18] S. Achilefu, R.B. Dorshow, J.E. Bugaj and R. Rajagopalan, Novel receptor-targeted fluorescent contrast agents for in vivo tumor imaging, Invest. Radiol. 35 (2000), pp. 479-485.

[19] R.K. Jain, Barriers to drug delivery in solid tumors, Sci. Am. 271 (1994), pp. 58-65.

[20] M.H. Kraus, N.C. Popescu, S.C. Amsbaugh and C.R. King, Overexpression of the EGF receptor-related proto-oncogene erbB-2 in human mammary tumor cell lines by different molecular mechanisms, EMBO J. 6 (1987), pp. 605-610.

[21] A. Levitzki, EGF receptor as a therapeutic target, Lung Cancer 41 (Suppl. 1) (2003), pp. S9-S14.

[22] N.J. Maihle, A.T. Baron, B.A. Barrette, C.H. Boardman, T.A. Christensen, E.M. Cora, J.M. Faupel-Badger, T. Greenwood, S.C. Juneja, J.M. Lafky, H. Lee, J.L. Reiter and K.C. Podratz, EGF/ErbB receptor family in ovarian cancer, Cancer Treat. Res. 107 (2002), pp. 247-258.

[23] A.P. Kyritsis and H. Saya, Epidemiology, cytogenetics, and molecular biology of brain tumors, Curr. Opin. Oncol. 5 (1993), pp. 474-480.

[24] G. Di Lorenzo, G. Tortora, F.P. D’Armiento, G. De Rosa, S. Staibano, R. Autorino, M. D'Armiento, M. De Laurentiis, S. De Placido, G. Catalano, A.R. Bianco and F. Ciardiello, Expression of epidermal growth factor receptor correlates with disease relapse and progression to androgen-independence in human prostate cancer, Clin. Cancer Res. 8 (2002), pp. 3438-3444.

[25] R.G. Thorne, S. Hrabětová and C. Nicholson, Diffusion of epidermal growth factor in rat brain extracellular space measured by integrative optical imaging, J. Neurophysiol. 92 (2004), pp. 3471-3481.
[26] S. Ke, X. Wen, M. Gurfinkel, C. Charnsangavej, S. Wallace, E.M. Sevick-Muraca and C. Li, Near-infrared optical imaging of epidermal growth factor receptor in breast cancer xenografts, Cancer Res. 63 (2003), pp. 7870-7875.

[27] J.L. Kovar, M.A. Johnson, W.M. Volchek, J. Chen and M.A. Simpson, Hyaluronidase expression induces prostate tumor metastasis in an orthotopic mouse model, Am. J. Pathol. 169 (2006), pp. 1415-1426.

[28] J.L. Kovar, W.M. Volcheck, J. Chen and M.A. Simpson, Purification method directly influences effectiveness of an epidermal growth factor-coupled targeting agent for noninvasive tumor detection in mice, Anal. Biochem. 361 (2007), pp. 47-54.

[29] D. Citrin, T. Scott, M. Sproull, C. Menard, P.J. Tofilon and C. Camphausen, In vivo tumor imaging using a near-infrared-labeled endostatin molecule, Int. J. Radiat. Oncol. Biol. Phys. 58 (2004), pp. 536-541.

[30] A. Petrovsky, E. Schellenberger, L. Josephson, R. Weissleder and A. Bogdanov, Near-infrared fluorescent imaging of tumor apoptosis, Cancer Res. 63 (2003), pp. 1936-1942.

[31] V. Ntziachristos, E.A. Schellenberger, J. Ripoll, D. Yessayan, E. Graves, A. Bogdanov, L. Josephson and R. Weissleder, Visualization of antitumor treatment by means of fluorescence molecular tomography with an annexin V-Cy5.5 conjugate, Proc. Natl. Acad. Sci. USA 101 (2004), pp. 12294-12299.

[32] G. Kostenich, N. Livnah, T.A. Bonasera, T. Yechezkel, Y. Salitra, P. Litman, S. Kimel and A. Orenstein, Targeting small cell lung cancer with fluorescent analogues of somatostatin, Lung Cancer 50 (2005), pp. 319-328.

[33] C. Grötzinger and B. Weidenmann, Somatostatin receptor targeting for tumor imaging and therapy, Ann. N. Y. Acad. Sci. 1014 (2004), pp. 258-264.

[34] H. Jin and J. Varner, Integrins: roles in cancer development and as treatment targets, Cancer Res. 90 (2004), pp. 561-565.

[35] R.E. Nisato, J.C. Tille, S.L. Goodman and M.S. Pepper, $\alpha_{\mathrm{v}} \beta_{3}$ and $\alpha_{\mathrm{v}} \beta_{5}$ Integrin antagonists inhibit angiogenesis in vitro, $\mathrm{An-}$ giogenesis 6 (2003), pp. 105-119.

[36] R.A. Cairns, R. Khokha and R.P. Hill, Molecular mechanisms of tumor invasion and metastasis: an integrated view, Curr. Mol. Med. 3 (2003), pp. 659-671.

[37] X. Chen, P.S. Conti and R.A. Moats, In vivo near-infrared fluorescence imaging of integrin alpha $\mathrm{v}$ beta 3 in brain tumor xenografts, Cancer Res. 64 (2004), pp. 8009-8014.

[38] R. Pasqualini, E. Koivunen and E. Ruoslahti, $\alpha_{v}$ Integrins as receptors for tumor targeting by circulating ligands, Nat. Biotechnol. 15 (1997), pp. 542-546.

[39] R. Falcioni, A. Antonini, P. Nistico, S. Di Stefano, M. Crescenzi, P.G. Natali and A. Sacchi, $\alpha_{6} \beta_{4}$ and $\alpha_{6} \beta_{1}$ Integrins associate with Erb-2 in human carcinoma cell lines, Exp. Cell Res. 236 (1997), pp. $76-85$.

[40] D.A. Cheresh, R. Pytela, M.D. Pierschbacher, F.G. Klier, E. Ruoslahti and R.A. Reisfeld, An arg-gly-asp-directed receptor on the surface of human melanoma cells exists in a divalent cation-dependent functional complex with the sisialoganglioside GD2, J. Cell Biol. 105 (1987), pp. 1163-1173.

[41] S. Achilefu, S. Bloch, M.A. Markiewicz, T. Zhong, Y. Ye, R.B. Dorshow, B. Chance and K. Liang, Synergistic effects of light-emitting probes and peptides for targeting and monitoring integrin expression, Proc. Natl. Acad. Sci. USA 102 (2005), pp. 7976-7981. 
[42] J.P. Houston, S. Ke, W. Wang, C. Li and E.M. Sevick-Muraca, Quality analysis of in vivo near-infrared fluorescence and conventional gamma images acquired using a dual-labeled tumortargeting probe, J. Biomed. Optics 10 (2005), pp. 045020054010 .

[43] S. Tyagi and F.R. Kramer, Molecular beacons: probes that fluoresce upon hybridization, Nat. Biotechnol. 14 (1996), pp. 303308.

[44] S. Tyagi, D.P. Bratu and F.R. Kramer, Multicolor molecular beacons for allele discrimination, Nat. Biotechnol. 16 (1998), pp. 49-53.

[45] R. Weissleder, C.-H. Tung, U. Mahmood and A. Bogdanov, In vivo imaging of tumors with protease-activated near-infrared fluorescent probes, Nat. Biotechnol. 17 (1999), pp. 375-378.

[46] D. Keppler, M. Sameni, K. Moin, T. Mikkelsen, C. Diglio and B. Sloane, Tumor progression and angiogenesis: cathepsin B \& Co, Biochem. Cell Biol. 74 (1996), pp. 799-810.

[47] J. Kim, W. Yu, K. Kovalski and L. Ossowski, Requirement for specific proteases in cancer cell intravasation as revealed by a novel semiquantitative PCR-based assay, Cell 94 (1998), pp. 353-362.

[48] E. Liaudet, D. Deroq, H. Rochefort and M. Garcia, Transfected cathepsin D stimulates high density cancer cell growth by inactivating secreted growth inhibitors, Cell Growth Differ. 6 (1995), pp. 1045-1052.

[49] M. Garcia, N. Platet, E. Liaudet, V. Laurent, D. Deroq, J. Brouillet and H. Rochefort, Biological and clinical significance of cathepsin D in breast cancer metastasis, Stem Cells 14 (1995), pp. 642-650.

[50] U. Mahmood and R. Weissleder, Near-infrared optical imaging of proteases in cancer, Mol. Cancer Therapeutics 2 (2003), pp. 489-496.

[51] C. Bremer, S. Bredow, U. Mahmood, R. Weissleder and C.H. Tung, Optical imaging of matrix metalloproteinase-2 activity in tumors: feasibility study in a mouse model, Radiology 221 (2001), pp. 523-529.

[52] C. Bremer, C.H. Tung, A. Bogdanov and R. Weissleder, Imaging of differential protease expression in breast cancers for detection of aggressive tumor phenotypes, Radiology 222 (2002), pp. 814-818.

[53] A. Becker, C. Hessenius, K. Licha, B. Ebert, U. Sukowski, W. Semmler, B. Wiedenmann and C. Carsten Grötzinger, Receptortargeted optical imaging of tumors with near-infrared fluorescent ligands, Nat. Biotechnol. 19 (2001), pp. 327-331.

[54] W. Yun, C. Weibo and C. Xiaoyuan, Near infrared imaging of tumor integrin $\alpha_{\mathrm{v}} \beta_{3}$ expression with Cy7 labeled RGD multimers, Mol. Imaging Biol. 8 (2006), pp. 226-236.

[55] H. Chen, J. Kovar, S. Sissons, K. Cox, W. Matter, F. Chadwell,
P. Luan, C.J. Vlahos, A. Schutz-Geschwender and D.M. Olive, A cell-based immunocytochemical assay for monitoring kinase signaling pathways and drug efficacy, Anal. Biochem. 338 (2005), pp. 136-142.

[56] S.P. Flanagan, "Nude," a new hairless gene with pleiotropic effects in the mouse, Genet. Res. 8 (1966), pp. 295-309.

[57] G.C. Bosma, R.P. Custer and M.J. Bosma, A severe combined immunodeficiency mutant in the mouse, Nature 301 (1993), pp. 527-530.

[58] T. Blunt, N.H. Finnie, G.E. Taccioli, G.C. Smith, J. Demengeot, T.M. Gottlieb, R. Mizuta, A.J. Varghese, F.W. Alt, P.A. Jeffo and S.P. Jackson, Defective DNA-dependent protein kinase activity is linked to V(D)J recombination and DNA repair defects associated with the murine scid mutation, Cell 80 (1995), pp. 813823.

[59] P. Mombaerts, J. Iacomini, R.S. Johnson, K. Herrup, S. Tonegawa and V.E. Papaioannou, RAG-1-deficient mice have no mature B and T lymphocytes, Cell 68 (1992), pp. 869-877.

[60] Y. Shinkai, G. Rathbun, K.P. Lam, E.M. Oltz, V. Stewart, M. Mendelsohn, J. Charron, M. Datta, F. Young, A.M. Stall and F.W. Alt, RAG-2-deficient mice lack mature lymphocytes owing to inability to initiate V(D)J rearrangement, Cell 68 (1992), pp. 855-867.

[61] M.F. Kircher, U. Mahmood, R.S. King, R. Weissleder and L. Josephson, A multimodal nanoparticle for preoperative magnetic resonance imaging and intraoperative optical brain tumor delineation, Cancer Res. 63 (2003), pp. 8122-8125.

[62] A.M. De Grand and J.V. Frangioni, An operational near infrared fluorescence imaging system prototype for large animal surgery, Technol. Canc. Res. Treatment 2 (2003), pp. 1-9.

[63] E.L. Rosenthal, B.D. Kulbersh, R.D. Duncan, W. Zhang, J.S. Magnuson, W.R. Carroll and K. Zinn, In vivo detection of head and neck cancer orthotopic xenografts by immunofluorescence, Laryngoscope 116 (2006), pp. 1636-1641.

[64] C.-H. Tung, Q. Zeng, K. Shah, D.-E. Kim, D. Schellingerhout and R. Weissleder, In Vivo Imaging of $\beta$-Galactosidase Activity Using Far Red Fluorescent Switch, Cancer Res. 64 (2003), pp. 1579-1584.

[65] A.B. Thompson, D.J. Hawrysz and E.M. Sevick-Muraca, Near infrared fluorescence contrast-enhanced imaging with area illumination and area detection: the forward imaging problem, $J$. Appl. Optics 42 (2003), pp. 4125-4136.

[66] Y. Chen, X. Intes and B. Chance, Development of high-sensitivity near infrared fluorescence imaging device for early cancer detection, Biomed. Instrumentation Technol. 39 (2005), pp. $75-85$.

[67] R. Weissleder, Molecular Imaging in cancer, Science 312 (2006), pp. 1168-1171. 